\title{
STUDY OF MEDICATION ERRORS BY PROSPECTIVE OBSERVATIONAL APPROACH IN WARANGAL HOSPITALS
}

\author{
SHIVANI RAVULA ${ }^{1}$, AKHILA JANGA ${ }^{2}$, RAJASEKHAR POONURU ${ }^{3 *}$
}

${ }^{1}$ Department of Pharmacy Practice, St. Peter's Institute of Pharmaceutical Sciences, Warangal, Telangana, India. ${ }^{2}$ Department of Pharm D, Rohini Multispecialty Hospitals, Warangal, Telangana, India. ${ }^{3}$ Department of Pharmaceutics, St. Peter's Institute of Pharmaceutical Sciences, Warangal, Telangana, India. Email: yuppieraj@gmail.com

Received: 05 February 2020, Revised and Accepted: 30 March 2020

ABSTRACT

Objective: The objective of the study was to determine the prevalence of medication errors occurring in a multispecialty hospital in Warangal.

Methods: A prospective observational study was conducted in Rohini Superspeciality Hospital, Hanamkonda, Warangal, from October 2018 to March 2019 , to study the prevalence of medication errors.

Results: In this study, 500 patients were selected, of which 160 were identified with medication errors. Two hundred and seventy-one medication errors were identified among these patients, of which 100 (60.63\%) patients were male and 24.37\% of patients were female.

Conclusion: This present study manifests that medication errors were predominate in males than in females and also the common age group was 50-60 years.

Keywords: Medication errors, Prospective approach, Observational study, Medication error reporting systems.

(C) 2020 The Authors. Published by Innovare Academic Sciences Pvt Ltd. This is an open access article under the CC BY license (http://creativecommons. org/licenses/by/4. 0/) DOI: http://dx.doi.org/10.22159/ajpcr.2020.v13i6.37046

\section{INTRODUCTION}

Medication error reporting systems are an internationally recognized tool for health-care professionals that are very promising in sharing serious medication errors occurring at places of medical practice. Drugs prescribed for various ailments can be given alone or in combinations and improper discharge of drugs can lead to medication errors which might elevate the risk potential of a therapy [1]. Efficacy which is measured as the level of benefit to patient and toxicity which is recognized as risk always happen collectively. Medical errors are preventable when proper assessment of their use is done. As per Leape's medication, error is an unintended act or an act that does not achieve its intended outcome. International studies had established that the medication error rate in observational studies ranges from 9 to $12 \%$ [2]. Indian patients were in palliative care for more than 2 decades, but tools to minimize medication errors are still to be explored [3]. Wannmacher et al. stated that prevention of medication errors and their frequency of occurrence is the best method to avoid the drastic consequences which might lead to compromise safety [4-7].

Miscommunication takes a major lead in generating diagnostic and treatment errors. In India, studies were carried out in Uttarakhand and Karnataka which documented medication error rate as high as $25.7 \%$ and $15.34 \%$, respectively, in hospitalized patients. Unfortunately, most of the medication errors remain undetected, if outcome or clinical significance does not adversely affect the patient. Some of the medication errors result in serious morbidity or mortality and also had a significant economic impact on the patient and health-care system. The Institute of Medicine estimated the costs due to medical errors in the US as approximately $\$ 37.6$ billion/year and about $\$ 17$ billion of it are associated with preventable errors [8-13]. Overall, medication errors increase morbidity, mortality, and economic burden on the health-care system [14-16].

Coimbra et al. observed and stated that spontaneous reporting, treatment chart review, review of medical prescriptions, and direct observation are the main methods for the identification and evaluation of medication errors [17]. Intervention in the field of medication errors such as a review process to remove unnecessary hazardous drugs from wards, hospital information systems for medication ordering and training of patients on the therapy have resulted in reduction of medication errors by $50 \%$ [18]

\section{METHODS}

Place of study and study design

The study was conducted in in-patients of Rohini Superspecialty Hospital located in Hanamkonda. A prospective observational study was carried out for a period of 6 months from October 2018 to March 2019.

\section{Study population}

Irrespective of the gender, age, and diseases in-patients of the general medicine department were included in the study. Pregnant women and psychiatric patients, outpatients, patients in the medical intensive care unit, and in-patients without medication therapy were excluded from the study.

\section{Study procedure}

During the study, data collection forms were collected and inpatient case records were reviewed, which includes patient's case history, diagnosis, physician medication order sheets, nurse medication administration records, and progress chart and laboratory investigations. This information was documented in the patient profile form and assessed for medication errors such as omission errors, wrong time errors, unauthorized drug error, improper dose error, wrong dosage form error, wrong drug preparation error, wrong administration technique, and other errors. Case records were followed from the date of admission till the date of discharge of the patient and observed medication errors were transferred to medication error reporting form and analyzed for the following parameters such as age and gender, number of medication per prescription, and type of medication errors. 
Statistical analysis

Percentage analysis was used and tables and graphs were designed according to the values observed.

\section{RESULTS}

From the study conducted by Zakharov et al., the error rate was $39.1 \%$. During the study period, a total of 500 patients were reviewed in all wards in Rohini Superspecialty Hospital. One hundred and sixty patients out of 500 patients were identified with medication errors. Among them, 271 medication errors were identified in 160 patients. Of the data collected from 160 patients, $100(60.63 \%)$ patients were male and $60(24.37 \%)$ patients were female.

\section{Age distribution}

One hundred and sixty patients with medication errors according to their age and number of errors in that particular age group were distributed.

Highest number of medication errors was found in 50-60 age group patients, $44(27.50 \%)$ with number of patients being $69(25.46 \%)$ errors. Among 40-50 age group patients, 43 (26.87\%) patients were reported with $67(24.72 \%)$ errors.

\section{Number of medication errors}

More than 1 error in each patient is identified. It includes prescription error, transcription error, dispensing error, and administration error. Patients with any one type of error considered as one error which leads to more errors were assessed as two, three, and four errors.

Out of 160 patients, 123 (76.87) patients with one error, followed by patients with two errors $30(18.75 \%)$ and patient with three errors $5(3.12 \%)$ and patients with four errors 2 (1.25\%) as shown in Fig. 1.

A total 1952 medication doses are observed in 160 patients and number of errors in doses is found to be 381 . The frequency of medication error was identified using the following formula.
Frequency of medication error=No. of errors in doses/Total no. of doses in patients with medication errors. The error frequency rate was found in our study as $381 / 9152 * 100=4.16$

Administration errors were noted 136 (50.18\%) making it the top most medication errors, followed by prescription error 94 (34.68\%), transcription error 19 (7.01\%), and dispensing error $22(8.11 \%)$ as shown in Fig. 2 and Fig. 3.

\section{Distribution of prescription errors}

According to Krithi Malhotra, due to lack of concentration (41\%) and because of many customers (53\%), the practitioner tends to fail in knowing the complete patient information which leads to prescription errors [19]. Out of 271 medication errors, prescription errors were found to be 94 and these prescription errors were assessed and classified into their subtypes:

1. Drug-drug interactions $81(86.17 \%)$ and

2. Incomplete information 13 (4.79\%).

\section{Distribution of transcription errors}

Out of 271 medication errors, transcription errors were identified to be 19 and these prescription errors were assessed and classified into wrong time, wrong dosage form, wrong preparation, wrong frequency, and wrong drug errors.

Out of 16 transcription errors, omission error contributes the highest transcription errors 7 (38.84\%), followed by wrong frequency, wrong dose 4 (25\%), wrong drug, wrong dosage form and wrong preparation, and wrong time $1(6.25 \%)$ were found to be the same.

\section{Distribution of dispensing errors}

Out of 271 medication errors, dispensing errors were found to be 22 and the same were assessed and classified into wrong dose, wrong ward, wrong dosage form, and wrong drug.

Out of 22 dispensing errors, wrong ward was noted 19 (86.3\%) making it at the top most medication dispensing error, followed by wrong dose

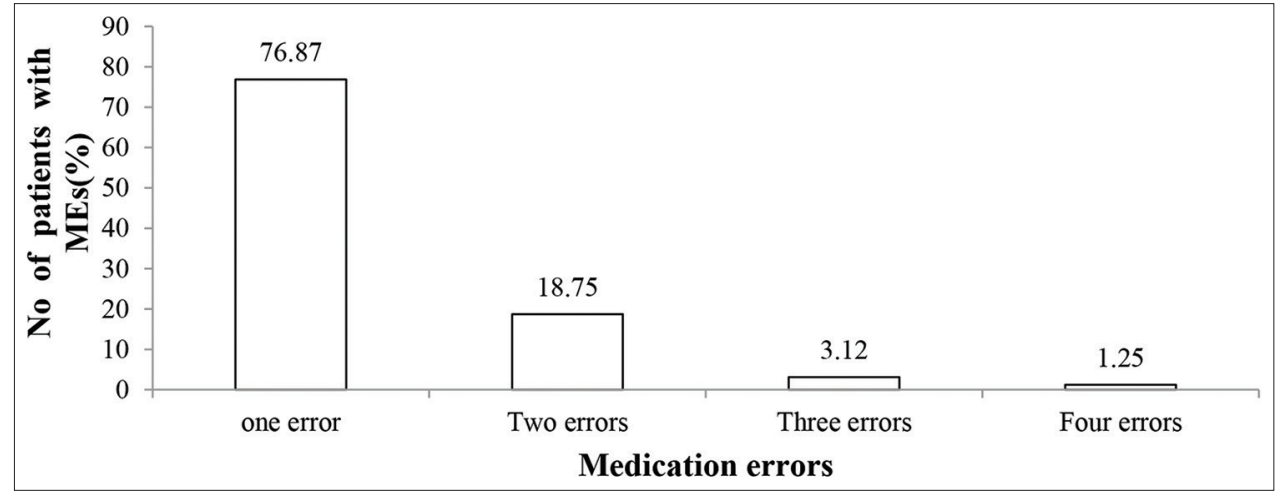

Fig. 1: Medication errors in each patient

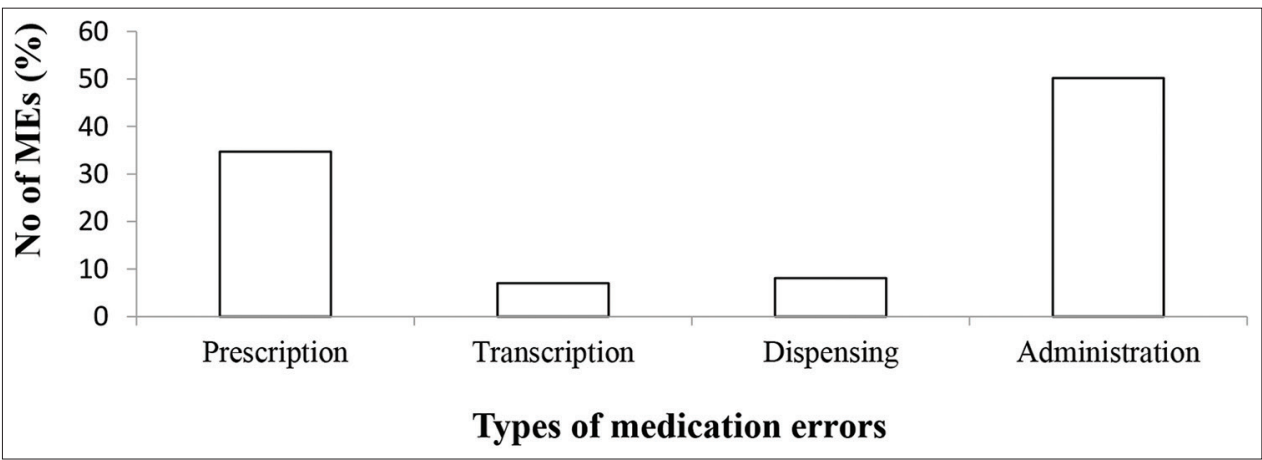

Fig. 2: Types of medication errors 


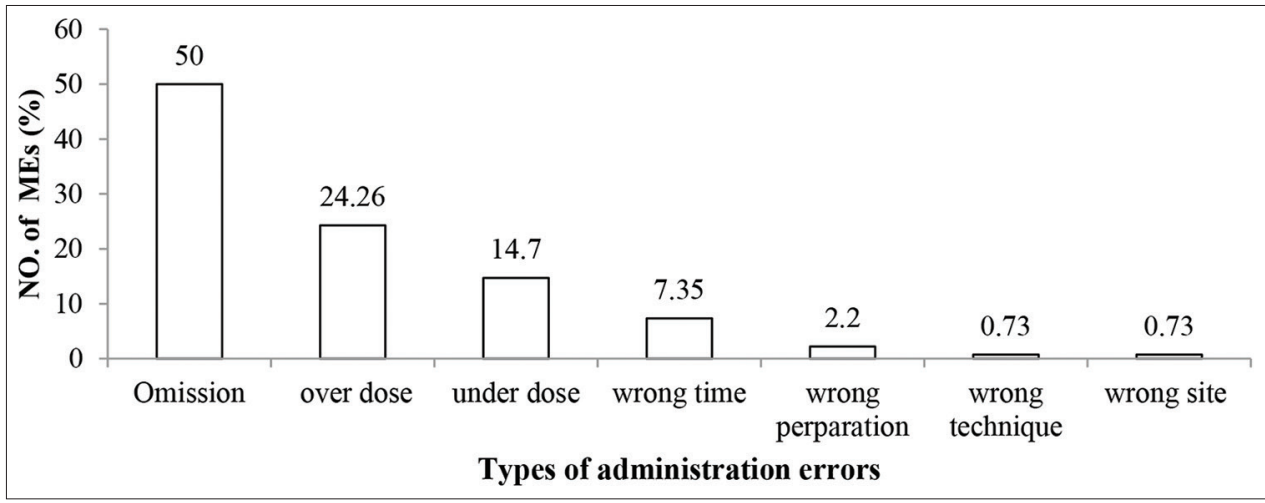

Fig. 3: Administration errors

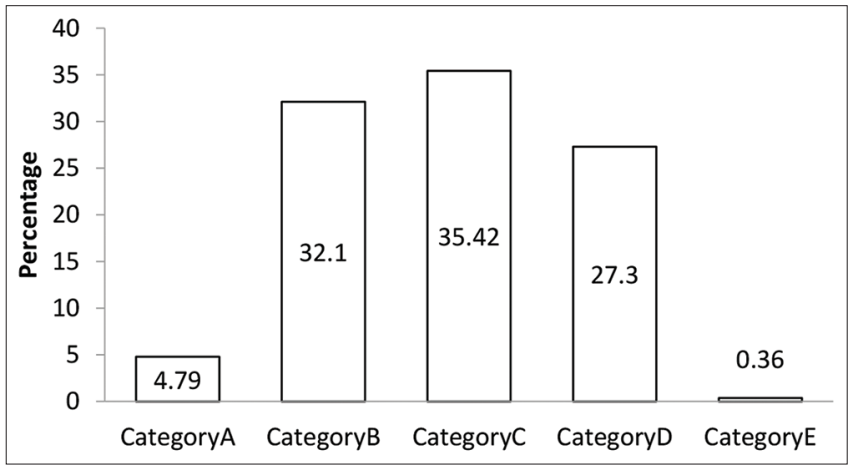

Fig. 4: National Coordinating Council for Medication Error Reporting and Prevention categorization

1 (4.54\%), wrong dosage form 1 (4.54\%), and wrong drug 1 (4.54\%) as shown in Table 1.

\section{Distribution of administration errors}

Out of 271 medication errors, administration errors were found to be 136 and these errors were assessed and classified into omission, overdose, underdose, wrong preparation, wrong time, wrong technique, and wrong site. According to Johari, right time knowledge was tested on questionnaire, in which IV antibiotic was given 4 times/day, 95.8\% were right time, and $4.2 \%$ served at wrong time [20].

Out of 129 medication administration errors, omission error observed to be $>1 / 2$ of medication administration errors $68(50 \%)$ and the least were of wrong site $1(0.73 \%)$ as shown in Table 2 .

National Coordinating Council for Medication Error Reporting and Prevention (NCCMERP) categorization of medication errors

Patients were reviewed on daily basis for medication errors and then the same were analyzed using NCCMERP taxonomy and categorized into various categories, as shown in Fig. 4.

A total of 271 errors were found and most of the errors belong to Category C 96 (35.42\%), followed by Category B 87 (32.10\%), Category D74 (27.30\%), Category A 13 (4.79\%), and Category E 1 (0.36\%).

\section{Contributing risk factors for medication errors}

After multidisciplinary reviews of medication errors which help to identify underlying causes or factors that might have contributed to the event were assessed, as shown in Fig. 5

Out of all risk factors, performance deficit contributes the highest 92 (33.94\%), which led to medication errors, followed by lack of knowledge 81 (29.88\%), heavy work load 47 (17.34\%), lack of concentration 39 (14.39\%), interruption 7 (2.58\%), knowledge deficit in dose calculation 4 (1.47\%), and undertrained 1 (0.36\%).
Table 1: Details of dispensing errors

\begin{tabular}{llll}
\hline S. No. & Types of dispensing errors & $\begin{array}{l}\text { No. of error } \\
(\mathbf{n = 2 2})\end{array}$ & Percentage \\
\hline 1. & Wrong ward & 19 & 86.36 \\
2. & Wrong dosage & 1 & 4.54 \\
3. & Wrong dosage form & 1 & 4.54 \\
4. & Wrong drug & 1 & 4.54 \\
\hline
\end{tabular}

Table 2: Details of transcription errors

\begin{tabular}{llll}
\hline S. No. & Type of transcription errors & $\begin{array}{l}\text { No. of error } \\
(\mathbf{n = 1 9 )}\end{array}$ & Percentage \\
\hline 1. & Omission & 7 & 36.84 \\
2. & Wrong frequency & 4 & 25 \\
3. & Wrong dose & 4 & 25 \\
4. & Wrong time & 1 & 6.25 \\
5. & Wrong dosage form & 1 & 6.25 \\
6. & Wrong preparation & 1 & 6.25 \\
7. & Wrong drug & 1 & 6.25 \\
\hline
\end{tabular}

Personnel involved in medication errors

Medication errors may occur at any stage, i.e., while prescribing, dispensing, and administering of drugs and persons involved in this process have been identified and assessed. L. La Pietra, in their article which states that, failures in communication sometimes relate directly to poorly written prescriptions.

In most of the medication errors, nurses were involved 154 (56.82\%), followed by prescriber $94(34.68 \%)$, pharmacist $(8.11 \%)$, and patient $(0.36 \%)$ as shown in Table 3.

\section{Duration of medication errors}

Duration of medication errors indicates information about which stage medication errors have been identified and stopped and also measures to be taken to prevent further errors which may occur due to the previous errors occurred.

Out of 271 medication errors, most of the errors were identified and stopped initially $54(26.34 \%)$ then followed by 1 day $52(25.36 \%), 1$ dose $36(17.56 \%)$ then errors continued for 2 days 36 (17.56\%), 3 days $18(8.7 \%)$, and 4 days 9 (4.39\%) as shown in Table 4 .

Distribution of medication class involved in medication errors In 271 medication errors, many drugs were involved. These drugs have been classified into their therapeutic class after assessing which were found to be cardiovascular (CVS) drugs, anti-platelets, antibiotics, anti-inflammatory drugs, antifungal, gastrointestinal (GI) drugs, bronchodilators, corticosteroids, anti-neoplastic, vitamins CNS agents, diuretics, antidiabetic, and miscellaneous drugs. In a study conducted by Patel et al., antibacterial (70\%) was the most common inappropriately prescribed drug group followed by GI (30\%) [20-26]. 


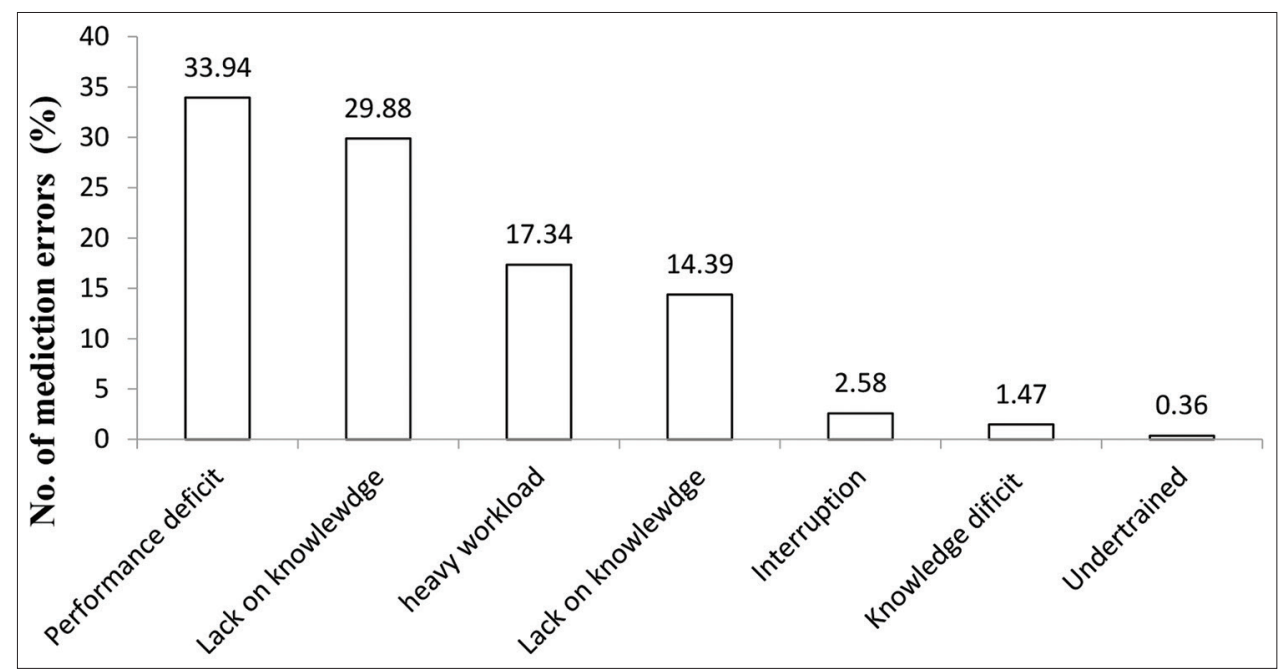

Fig. 5: Contributing risk factors

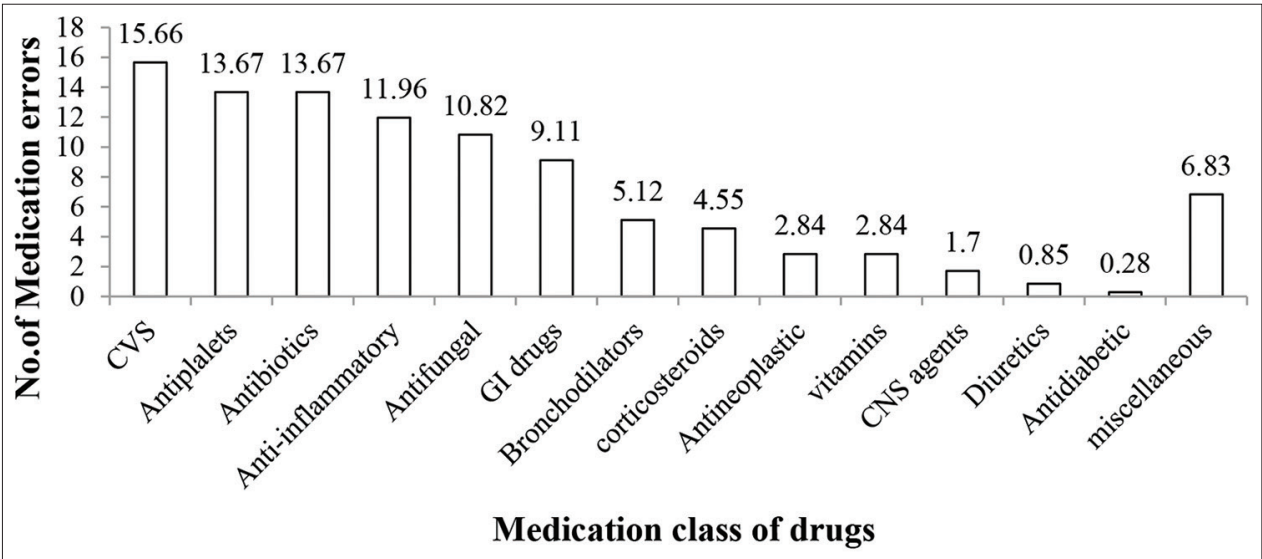

Fig. 6: Medication classes involved in medication errors

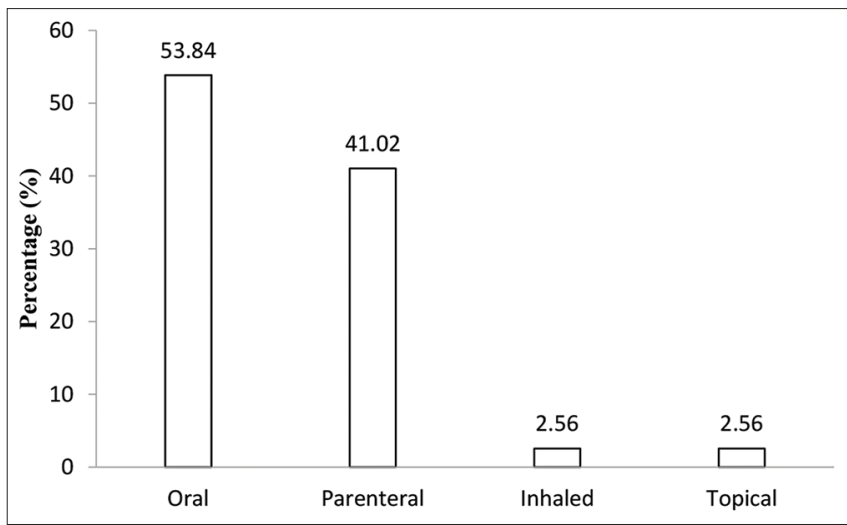

Fig. 7: Types of dosage forms involved in medication error

The study of involvement of a particular medication class to the medication errors showed that the CVS drugs 55 (15.66\%) contributing maximum, which was followed by anti-platelets $48(13.67 \%)$ and antibiotics 48 (13.67\%) as shown in Fig. 6.

\section{Generic versus brand}

All the drugs involved in medication errors were distributed into brand and generic names. A total of 329 (93.73\%) errors were found to be due to brand and $22(6.26 \%)$ were found to be generic. Out of 271 medication errors, many drugs dosage forms were involved.
Table 3: Details of personnel involved in medication errors

\begin{tabular}{llll}
\hline S. No. & personnel involved & No. of errors $(\mathbf{n = 2 7 1 )}$ & Percentage \\
\hline 1. & Prescriber & 94 & 34.68 \\
2. & Pharmacist & 22 & 8.11 \\
3. & Nurse & 154 & 56.82 \\
4. & Patient & 1 & 0.36 \\
\hline
\end{tabular}

Table 4: Details of duration of medication errors

\begin{tabular}{llll}
\hline S. No. & Duration & No. of errors $(\mathbf{n = 2 0 5})$ & Percentage \\
\hline 1. & Initially & 54 & 26.34 \\
2. & 1 dose & 36 & 17.56 \\
3. & 1 day & 52 & 25.36 \\
4. & 2 days & 36 & 17.56 \\
5. & 3 days & 18 & 8.78 \\
6. & 4 days & 9 & 4.39 \\
\hline
\end{tabular}

The dosage forms which were involved in most medication errors included oral drugs 189 (53.84\%) and injectable 144 (41.02\%) followed by inhaled drugs 9 (2.56\%) and topical 9 (2.56\%) as shown in Fig. 7.

\section{DISCUSSION}

Understanding of medical errors and patient safety has gained scientific attention in due course of time due to increased frequency of errors 
in medicine causing enormous financial costs and health hazards. In a review done by Karthikeyan, the incidence of nursing errors was ranged from $19 \%$ to $34 \%$, whereas in our study, it was higher and observed to be $56.82 \%$. According to Ngayen, wrong administration technique errors were $23.5 \%$, but this study had higher number of administration errors and was noted as $50.18 \%$ making it the top most medication errors. Patel in his study stated that prescribing errors $70.40 \%$ were the most frequently occurring type of error, in contrast, in this study, only $34.68 \%$ were observed out of all medication errors. The current study highlights the importance of identification of medical errors in a multisuperspecialty hospital which help in achieving better therapeutic outcomes and improved patient care.

\section{CONCLUSION}

Lack of facilities, resources, and infrastructure were the key points for the occurrence of medical errors. This study focused on the various types of errors and personnel involved which are possible drug-drug interactions; hence, complete review of past and present medical history is needed before writing a prescription to occur in a patient care setting. Most of the prescription related errors were found to be due to inaccurate administration which was due to performance deficit. This study indicates the clear need for the regular investigations, follow-ups that are to be done to rectify and minimize various types of medication errors.

\section{ACKNOWLEDGMENT}

We are thankful to St. Peter's Institute of Pharmaceutical Sciences for financial support. We also thank the management and medical staff of Rohini Super speaciality hospital, Vishwas Hospital and Shri Krishna Hospital, Warangal for providing access to collect data for scientific publication.

\section{AUTHORS' CONTRIBUTIONS}

Shivani Ravula and AkhilaJanga conceptualized the research idea, performed literature search; Rajasekhar Poonuru wrote and edited the manuscript, revised the manuscript, and acted as the corresponding author.

\section{CONFLICTS OF INTEREST}

The authors declare that there are no conflicts of interest.

FUNDING

This research did not receive any specific grant from funding agencies in the public, commercial, or non-for-profit sectors.

\section{REFERENCES}

1. Bates DW, Boyle D, Vander VM, Schneider J, Leape L. Relationship between medication errors and adverse drug events. J Gen Intern Med 1995; 10:199-205.

2. Lesar T. Medication-prescribing errors in a teaching hospital. A 9-year experience. Arch Intern Med 1997;157:1569-76.

3. Khosla D, Patel FD, Sharma SC. Palliative care in India: Current progress and future needs. Indian J Palliat Care 2012;18:149-54

4. Inch J, Watson MC, Anakwe-Umeh S. Patient versus healthcare professional spontaneous adverse drug reaction reporting: A systematic review. Drug Saf 2012;35:807-18.
5. Gandhi TK, Weingart SN, Borus J, Seger AC, Peterson J, Burdick E, et al. Adverse drug events in ambulatory care. $\mathrm{N}$ Engl $\mathrm{J}$ Med 2003;348:1556-64.

6. Claesson CB, Burman K, Nilsson JL, Vinge E. Prescription errors detected by Swedish pharmacists. Int J Pharm Pract 1995;3:151-6.

7. Khoja T, Neyaz Y, Qureshi NA, Magzoub MA, Haycox A, Walley T. Medication errors in primary care in Riyadh city, Saudi Arabia. East Mediterr Health J 2011;17:156-9.

8. Chan M, Nicklason F, Vial JH. Adverse drug events as a cause of hospital admission in the elderly. Intern Med J 2001;31:199-205.

9. Lu CY, Roughead E. Determinants of patient-reported medication errors: A comparison among seven countries. Int J Clin Pract 2011;65:733-40.

10. Royal S, Smeaton L, Avery AJ, Hurwitz B, Sheikh A. Interventions in primary care to reduce medication related adverse events and hospital admissions: Systematic review and meta-analysis. Qual Saf Health Care 2006;15:23-31.

11. Bates DW, Miller EB, Cullen DJ, Burdick L, Williams L, Laird NP, et al. Patient risk factors for adverse drug events in hospitalized patients. ADE prevention study group. Arch Intern Med 1999;159:2553-60.

12. Barach P, Small SD. Reporting and preventing medical mishaps: Lessons from non-medical near miss reporting systems. Br Med J 2000;320:759-63.

13. Zakharov S, Tomas N, Pelclova D. Medication errors-an enduring problem for children and elderly patients. Ups J Med Sci 2012;117:309-17.

14. Gor AP, Desai SV. Adverse drug reactions (ADR) in the inpatients of medicine department of a rural tertiary care teaching hospital and influence of pharmacovigilance in reporting ADR. Indian J Pharmacol 2008; 40:37-40.

15. Hou JY, Cheng KJ, Bai KJ, Chen HY, Wu WH, Lin YM, et al. The effect of a computerized pediatric dosing decision support system on pediatric dosing errors. J Food Drug Anal 2013;21:286-91.

16. Kaushel R, Bates DW, Landrigon C, Mckenna KJ, Clapp MD, Federica F, et al. Medication errors and adverse drug events in pediatric inpatients. JAMA 2001;285:2114-20

17. Wilson D, McArtney R, Newcombe R, McArtney R, Gracie J, Kirk C, et al. Medication errors in paediatric practice: Insights from a continuous quality improvement approach. Eur J Pediatr 1998;157:769-74.

18. Woolf SH, Kuzel AJ, Dovey SM, Phillips RL. A string of mistakes: The cascade analysis in describing, counting, and preventing medical errors. Ann Fam Med 2004;2:317-26.

19. Mugada V, Devineni RC, Pendyala RM, Vempati D, Kuchi S. Categorization, appraisal, and reporting of medication errors ascertained in medical ward of tertiary care hospital. J App Pharm Sci 2018;8:109-14.

20. Rey MB, Prados YA, Gomez ES. Analysis of the medication reconciliation process conducted at hospital admission. Classification and variability of drug assessment reports on the GENESIS group. Farm Hosp 2016;40:246-59.

21. Layqah LA, Alakeel YS, Shamou JZ. The practice of counseling in pharmacy: Patients' perspectives. Asian J Res Pharm Sci 2018;8:170-6.

22. Ramadevi K, Kalyan VR, Abeer RM. A study on the effect of dietary factors on functional gastrointestinal disorders in women of hail region in Saudi Arabia. Asian J Pharm Clin Res 2018;11:202-7.

23. Vira T, Colquhoun M, Etchells E. Reconcilable differences: Correcting medication errors at hospital admission and discharge. Qual Saf Health Care 2006;15:122-6.

24. Praveena P, Usman S, Deepika B, Kumar R, Mohanta GP, Manna PK, et al. Impact of patient counselling on knowledge, attitude, practice and quality of life in patients with Type II diabetes mellitus and hypertension. Indian J Pharm Pract 2011;4:50-4.

25. Mihajlovic S, Gauthier J, MacDonald E. Patient characteristics associated with adverse drug events in hospital: An overview of reviews. Can J Hosp Pharm 2016;69:294-8

26. Francis J, Abraham S. Clinical pharmacists: Bridging the gap between patients and physicians. Saudi Pharm J 2014;22:600-2. 